\title{
Renal angiomyolipomas in tuberous sclerosis
}

\author{
Julia Röper-Kelmayr ${ }^{1 *}$, Thomas Sokol' ${ }^{2}$, Franz A. Fellner ${ }^{1,3}$ and Kaveh Akbari ${ }^{1}$ \\ ${ }^{1}$ Central Radiology Institute, Kepler University Hospital, Medical Faculty of the Johannes Kepler University, Linz, Austria \\ ${ }^{2}$ Department of Urology, Kepler University Hospital, Medical Faculty of the Johannes Kepler University, Linz, Austria \\ ${ }^{3}$ Medical Faculty of the Friedrich-Alexander-University of Erlangen-Nürnberg, Erlangen, Germany
}

\section{Case report}

We report 37-year-old patient with cortical and subependymal tubers suspicous for tuberous sclerosis. Tuberous sclerosis, also known as Bourneville's disease, is a phacomatosis with an incidence 1:6000 - 1:10000. Classical findings include the triad of adenoma sebaceum, seizures, and mental retardation. The inheritance is autosomal dominant; however, spontaneous mutation is described up to $66 \%$ [1-9].

Possible radiological findings in context with TS are multiple benign tumors, such as cardiac rhabdomyoma, renal angiomyolipoma, as well as neurological lesions: cortical and subependymal tubers accompanied by white matter changes (Figure 1). Furthermore, lymphangioleiomyomatosis, multifocal micronodular pneumocyte hyperplasia and renal cysts, as well as bone, liver and alimentary tract involvement may be found [2-5].

Moreover, the patient revealed multiple lesions in both kidneys, as found in abdominal ultrasound: Consecutive MR imaging confirmed the presence of multiple small lesions in both kidneys. These lesions showed high signal on T1-weighted in phase gradient-echo images and signal loss on opposed phase gradient-echo images (Figure 2), as found in fat containing benign tumors.

Renal angiomyolipomas are benign tumors with variable amounts of of abnormal vessels, immature smooth-muscle and fat cells. Angiomyolipomas usually are asymptomatic, when they are detected. However, follow-up, especially in case of large tumors, is obligatory due to the risk of rupture with consecutive bleeding [3,6]. In patients with tuberous sclerosis bilateral angiomyolipomas of the kidneys are found frequently (55-75\%) [1]. Due to the MR appearance of these lesions, the suspected diagnosis was bilateral renal angiomyolipoma in tuberous sclerosis.

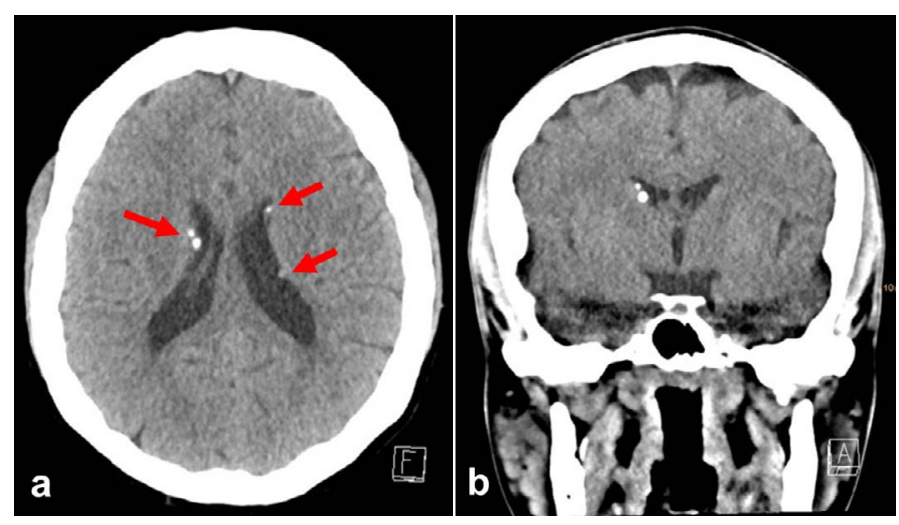

Figure 1. Non-contrast enhanced CCT in transverse orientation (a) and coronal reconstruction (b) shows typically small foci of calcification in the sense of subependymal tubers (arrows) in tuberous sclerosis.

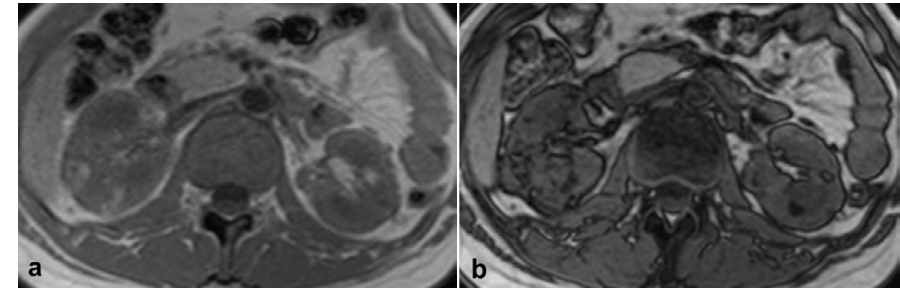

Figure 2. a: On T1-weighted gradient-echo in-phase imaging the lesions show high signal. b: On opposed-phase gradient-echo images the lesions reveal signal loss due to the presence of fat, as found in Angiomyolipomas.

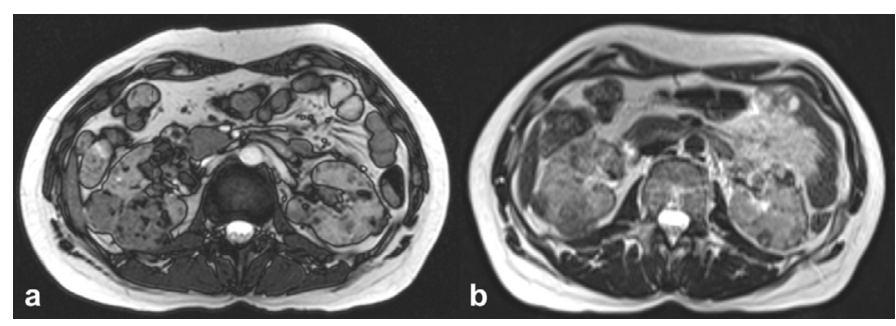

Figure 3. a: Initial MR examination, T2-weighted gradient-echo true FISP. b: Followup examination 6 months later, T2-weighted turbo spin-echo. The follow-up examination demonstrates size reduction of several lesions after therapy with Votubia ${ }^{\circledR}$ (everolimus).

An adequate therapy using Votubia (everolimus), which is recommended for the treatment of tuberous sclerosis patients with kidney tumors, was initiated [8]. Follow-up MR examinations showed size reduction in some of the lesions (Figure 3).

\section{Disclosure}

No conflicts of interest. No grants or financial supports.

\section{References}

1. Niederstadt T, Kurlemann G (2007) Neurocutaneous syndromes. Radiologie up2date 7: $247-264$.

2. Logue LG, Acker RE, Sienko AE (2003) Best cases from the AFIP: angiomyolipomas in tuberous sclerosis. Radiographics 23: 241-246. [Crossref]

3. Umeoka S, Koyama T, Miki Y, Akai M, Tsutsui K, et al. (2008) Pictorial review of tuberous sclerosis in various organs. Radiographics 28: e32. [Crossref]

Correspondence to: Julia Röper-Kelmayr, Central Radiology Institute, Kepler University Hospital, Medical Faculty of the Johannes Kepler University, Linz, Austria, E-mail: julia.roeper-kelmayr@kepleruniklinikum.at

Key words: tuberous sclerosis, bourneville's disease, renal angiomyolipomas, magnetic resonance

Received: August 02, 2017; Accepted: August 10, 2017; Published: August 12, 2017 
4. Israel GM, Hindman N, Hecht E, Krinsky G (2005) The use of opposed-phase chemical shift MRI in the diagnosis of renal angiomyolipomas. AJR Am J Roentgenol 184: 18681872. [Crossref]

5. Sugimoto M, Takamura S (1997) Renal angiomyolipoma and renal cell carcinoma associated with tuberous sclerosis: a case report. Hinyokika Kiyo 43: 33-35. [Crossref]

6. Craig WD, Fanburg-Smith JC, Henry LR, Guerrero R, Barton JH (2009) Fat-containing lesions of the retroperitoneum: Radiologic-pathologic correlation. Radiographics 29: 261-290.
7. Outwater EK, Blasbalg R, Siegelman ES, Vala M (1998) Detection of lipid in abdominal tissues with opposed-phase gradient-echo images at 1.5T: techniques and diagnostic importance. Radiographics 18: 1465-1480. [Crossref]

8. Eijkemans MJ, van der Wal W, Reijnders LJ, Roes KC, van Waalwijk van DoornKhosrovani SB, et al. (2015) Long-term Follow-up assessing renal angiomyolipoma treatment patterns, morbidity, and mortality: an observational study in tuberous sclerosis complex patients in the Netherlands. Am J Kidney Dis 66: 638-645. [Crossref]

9. Narayanan V (2003) Tuberous sclerosis complex: genetics to pathogenesis. Pediatr Neurol 29: 404-409. [Crossref]

Copyright: $(2017$ Röper-Kelmayr J. This is an open-access article distributed under the terms of the Creative Commons Attribution License, which permits unrestricted use, distribution, and reproduction in any medium, provided the original author and source are credited. 